\section{Storms, hanged pirates, anemia, exsanguination: the contributions of Monro, Kellie and Abercrombie in understanding intracranial blood circulation}

\author{
Pasquale De Bonis, ${ }^{1}$ Carmelo Anile ${ }^{2}$ \\ ${ }^{1}$ Neurosurgery, S. Anna University \\ Hospital, Cona di Ferrara (FE); \\ ${ }^{2}$ Neurosurgery, Catholic University School \\ of Medicine, Rome, Italy
}

\begin{abstract}
The so-called Monro-Kellie doctrine states that with an intact skull, the sum of the volume of the brain plus the cerebrospinal fluid volume plus the intracranial blood volume is constant. Therefore an increase in one should cause a reduction in one or both of the remaining two. The researcher who expressed the doctrine in such a way was indeed Harvey Cushing in 1925, during a lecture in Edinburgh. The original Monro-Kellie doctrine is the result of observations on autopsies and several animal experiments. What the original doctrine states is a dynamic explanation of the intracranial system, aimed at explaining how a pulsatile and continuous perfusion may occur in a closed-non-expandable and fully filled system. During each cardiac cycle the quantity of blood within the head must be the same: during the systole, the brain arteries dilate, and, in the mean time, a quantity of blood, equal to that which is dilating them, is passing out of the head through the veins. During the succeeding diastole, the quantity which dilated the brain arteries passes into the corresponding veins and, at the same time, as much passes from the sinuses out of the head, as enters into the head from the arteries situated between the heart and the head. Monro implicitly states that the blood coming out from the cerebral veins into the sinuses must be pulsatile and (almost) synchronous with the arteries. That is deeply different from the concept of a constant content of a rigid case, as expressed by Cushing.
\end{abstract}

\section{Introduction}

When we, insiders, think on the so called Monro-Kellie doctrine, the first notions our minds make us deal with are that, with an intact skull, the sum of the volume of the brain plus the cerebral spinal fluid (CSF) volume plus the intracranial blood volume is constant. Therefore an increase in one should cause a reduction in one or both of the remaining two.

This law is now widely accepted and has been used as a physiological basis in order to explain what occurs in case of increased intracranial pressure (especially due to a foreign body, such as a tumor) or in case of decreased intracranial pressure, as in the case of CSF leaks (intracranial hypotension). ${ }^{1}$

This doctrine is very easy to be understood and has been expressed so as to be scientifically reproducible: a mathematical formula (brain vol + CSF vol + blood vol $=\mathrm{K}$ ).

Nonetheless, what the researches whose lasting eponymous fame was linked to this law demonstrated in their essays, was not exactly what that formula shows.

The researcher who expressed the doctrine in such a precise formula was indeed Harvey Cushing in 1925, during a lecture in Edinburgh. ${ }^{2}$ One could argue that both Monro and Kellie ignored the existence of the CSF. In fact, from the ancient times, based on Hippocrates (460-370 B.C.) and Galen (130200 A.D.), it was thought that cerebral ventricles were filled with pneuma psychikon (Latin: spiritus animalis), i.e. animal spirit. Despite several anatomists had described the presence of a fluid within the ventricles and/or around the spinal canal (Niccolò Massa in 1536, Thomas Willis in 1664, Marcello Malpighi in 1665, Antonio Valsalva in 1692, Antonio Pacchioni in 1705, Domenico Cotugno in 1764), the name cerebrospinal fluid was introduced by François Magendie in the first half of the $19^{\text {th }}$ century. ${ }^{3}$ Both Monro and Kellie describe the presence of serum fluid within the cranium. ${ }^{4,5}$

Despite this neglected aspect, the difference between the previous formula and the original doctrine is significant.

Both Monro and Kellie (together with another Scottish doctor: John Abercrombie), discuss about the blood circulation within the brain. Their conclusions are the logical consequence of observation performed during human autopsies and (in the case of Kellie and Abercrombie) animal experiments.

The doctrine is based on two principles: i) the brain is enclosed in a non-expandable case of bone; ii) the brain completely fills this case and is not compressible. In his article, Kellie describes that One of my oldest physiological recollections, indeed, is of this doctrine having been inculcated by my illustrious preceptor in anatomy, the second Monro, a doctrine which he used to illustrate by exhibiting a hollow glass ball, filled with water, and desiring his pupils to remark that not a drop of fluid escaped, when Inverted with its aperture downwards. Abercrombie (Kellie expressed this with very similar words) stated that: The cranium is a complete sphere of bone, which is
Correspondence: Pasquale De Bonis, Neurosurgery, S. Anna University Hospital, viale A. Moro 8, 44121 Cona di Ferrara, Italy.

Tel +39.0532236292.

E-mail: debonisvox@gmail.com.

Key words: Monro-Kellie doctrine, intracranial system, cerebral blood flow, cerebral autoregulation, intracranial veins.

Contributions: PDB, books search, manuscript writing, manuscript reviewing; CA, manuscript reviewing.

Conflict of interest: the authors declare no potential conflict of interests.

Received for publication: 30 August 2014.

Revision received: 16 November 2014.

Accepted for publication: 16 November 2014.

This work is licensed under a Creative Commons Attribution 3.0 License (by-nc 3.0).

(c) Copyright P. De Bonis and C. Anile, 2014

Licensee PAGEPress, Italy

Veins and Lymphatics 2014; 3:4682

doi:10.4081/vl.2014.4682

exactly filled by its contents, the brain, and by which the brain is closely shut up from atmospheric pressure, and from all influence from without except what is communicated through the blood vessels which enter it. ${ }^{6}$ Therefore the notion of a rigid case completely filled with the intracranial non-compressible content (the brain alone or brain plus fluids-blood and CSFbeing fluid non-compressible too) constituted the doctrine starting point instead of the conclusion. While it is quite simple to demonstrate that the case is non-expandable, on the brain non-compressibility Abercrombie stated that: in this investigation it is unnecessary to introduce the question, whether the brain is compressible, because we may safely assert that it is not compressible by any such force as can be conveyed to it from the heart through the carotid and vertebral arteries. ${ }^{6}$ The intracranial content can therefore be compared with a fluid, which is non-compressible (at least if the only available compressing force comes from the heart).

This raises a question: how can cerebral blood circulation occur, since at every heart systole a certain amount of blood enters the brain? The doctrine answers to this fundamental question.

Alexander Monro was the first to provide an explanation to this. Nonetheless, we have no demonstrations of how he drew his conclusions. Kellie himself writes that: It can scarcely be supposed that this doctrine should have been thus broadly maintained by so practiced an anatomist, so acute an observer, and so excel- 
lent a pathologist, to be, that, in the course of his very extensive experience, he had observed nothing in the appearances of the vascular system of the brain, under the varied circumstances of health and disease, which seemed to militate against the hypothesis. It is, at least, by such an appeal to nature that the merits of the hypothesis are to be tried. Therefore, Kellie (and, to a lesser extent, Abercrombie) demonstrated Monro's doctrine through autopsy findings and animal experiments.

\section{The autopsy findings by Kellie}

The first cases described by Kellie concern a man and a woman found dead after lying outside during a storm on November $4^{\text {th }}, 1821$. Kellie and his colleague Dr. Cheyne (the doctor who described the Cheyne-Stokes respiration) were asked by the magistrates to ascertain the cause of death. Kellie and Cheyne concluded that those individuals had died of torpor from cold. In the head, the same bloodless state of the scalp, the same turgidity of the vessels on the surface of the brain, - the same congestion of the sinuses, - the same soundness of the cerebral texture, - [...] But here, too, we find but little blood in the arteries, and the less perhaps the more the veins appear congested. It may, therefore, be concluded, that the blood which after death we find congested within one set of vessels in the brain, is just that quantity of blood which was circulated within the head, and at every instant of time distributed, in some proportion or other, between the arteries and veins during life.

In these cases the scalp was bloodless; in the intracranial space: the sinuses and the veins were congested while the arteries contained little blood.

A different condition was that of two pirates: Peter Heamen and Francois Gautiez, who were hanged on January $10^{\text {th }} 1821$ at Leith for piracy and murder (Figure 1).

Dr Monro very politely afforded me the opportunity of being present at the examination he was to make of the brain of one of them immediately after execution. I have remarked that one eye only of each subject was much reddened and suffused, and I observed also that the corresponding side of the face of each was evidently more livid than the other, and the truth of this observation was admitted by several of the gentlemen present, to whom I made the remark. The manner in which the instrument of death is adjusted affords, I think, a ready and natural explanation of the fact. As the noose of the cord is adjusted by the executioner on one side of the neck, it becomes, as it were, the point of suspension, so that, by the weight of the victim, it slips upwards from the neck on that side towards the mastoidal process behind the ear;

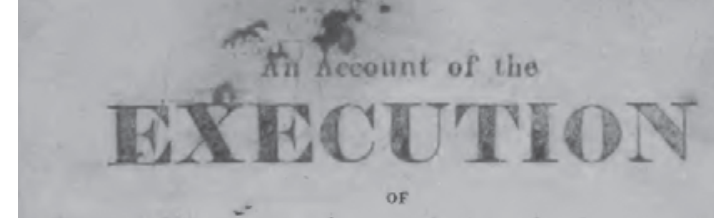

Peter Heamen, late of Sumderland, and Francois Gautiez, a Foreigner,

On THURSDAY last, on LEITH SANDS, Fon Piracy and Murder.

Figure 1. Original account of the execution of the two pirates.

N Tharday last (January 10th,) these two unfortnnate men were executed on a platform on the Sands of Leith,
within high water mark, for the crime of Piracy and Murder, pursanat to the sentence of the High Court of Admiralty. Between eight and nine o'clock the Magistracy and their attentants procreded from the Council Chamber to the Netw Jail, where a detachment of the $3 \mathrm{~d}$ Drag. Guards had arrived. About half past nime o'clock the great gate of the prison was thrown open, when thé procession procecded as follows :A detachment of Cavalry, A large party of the Police.

The City Oficers, with their halberts. the city in their wotse, with white gloven and whito the city in their roles, with white gloves and white staves,In the secost ware two gentlensen it attendance "pon the
Magistrates, and the Reverezd $\mathrm{M}$ W Wallace, a Roman Catholic Magistrater, and the Reveresd Mr Wallace, a Roman Carnosell, Clergyman. Che of the Mrinster
Chaplain of the jail.

A Cart, with a seat on the upper end, on which the criminals sat. also surrounded the cart, and a party of Dragoons.

The procession proceeded in this manner from the jail, alon of the Regent Brilge, down 1.eith Street, Leith W Walk and Constitution S/reet, to the Platiorm, which was erected at the

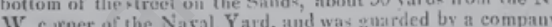
of the $415 t$.

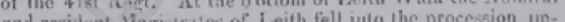
and resident, Mingivitrates of Leith felt into the procession imTumediatels upon ascending the sealfiad, the 51 ist patis ws given out by Di. Campbell, and sung, if which fieamen knceling was issisted in lis devotions by che clergyman who attended his

Upon the psalm being concluded, $\mathrm{Dr}$ Camploell addressed the spectators, in a mamer the most feeling and impressive, and well udupted to the solemn and metancholy occasion. In the course of his adides the Hr, ofverted be fied manner, his prticipation in the crine for which he vahic and unquakthe finirnerse of the trial, aut the justice of the sentence which had been pronounced.

Heamun then came forward, and bowing to all around lim, spoke for a short time. He cautioned all who lyeard lim to take a warang from the melancholy situation to which his crimes had reduced his, to abstain from bad company, his associating with whom, and disregarthe the primeiples and precepts of our holy religion, had been the means or bringing hin to

Dr Campbell then offered up a most impressise prayer, during which Heaman Kneeled. During the tims that Dr Camplelt adiressed the spertators, as well as while he enguged in prayer, and during the time that flenman spoke, fautiez was engaged with the clergy man who atiended him in acts of devotion, aceordiag to the forms of their religion, in which he seen ed very earnest, and which contmued a short time aiter Dr Campbell had
concluded lis prayers.

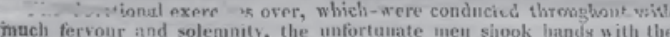
much fervour and solemnity, the unfortunate men siook hands with the magivtratex and clergyman around them, and mounted the fatal drop, whil. there, Hea man prayed aloud most firvently for some time. Heaman's last words were, "Lord Jesus receive iny soul." Upon prononncing which be shook hands with Gautiez, and then dropt the signal, when they were launched into eternity.

The behaviour of both the criminals was deent, resigned, and penitent. They were dressed in coloured elothes, Heaman in a brown jacket unil white trowsers, and Gautiez in a brown coat. The procession mosed at a slow rate down Leith $\mathbf{W}$ alk, and as Heamah passed the crowde collected at the corners of the different streets and lanes, and the people at windows, he stood up uncovered, and bowod respectfully. Cautiez seemed ahorbed in thought, and remained seated, taking little or no notice of any thing aronnd him. He appeared weak, and lor some time was smpported by a fran on the platfurm.

The crowd of spectators was immense, particnlarly on the Sands, being ner in which exery thing to finty thousand, but, owing to the excellent man-

During the execution, the great bell of Sonth Leith Church tolled ifer the unfortunate men were cut down, ofoir bodies were the unfortunate men were cut down, their bodies were conveyed under an
escort of dragoons, to Dr Munro's clase-room, for dissction putsuant to their sentence.

SVYMERS, PRINTER, SUNAERLAND 
and there is, consequently, a space on this side corresponding to the rising of the noose, which is not any, pressure. The mark of the rope, accordingly, did not form a circle round the whole neck, but was observed to rise obliquely upwards, behind the ear, on that side on which the eye was the least suffused, and the counte-

nance the least livid. On dividing the scalp the blood flowed freely, and in such quantity as to afford ample proof of the congestion of the vessels exterior to the cranium. [... J All the sinuses contained blood, but in no extraordinary quantity. The larger vessels on the surface, and between the convolutions of the brain, were but $\begin{array}{lllllllll}\text { G } & H & \text { A } & \text { P } & \text { T } & \text { E } & \text { R } & \text { I. }\end{array}$

\section{Of the Circulation of the Blood within the Head.}

\section{S E C T. I.}

I has been juftly obferved by authors, that the force of the blood fent to the brain and cerebcllum in man is broken by its afcent; by the angles at the rife of the internal carotid and vertebral arteries; by the turns which thefe form in their courfe, for inftance, by the turns of the internal carotids within the os perrofum and ar the fides of the fella turcica; and by the uncommonly great proportion which the fum of the areac of the branches bears to the area of the trunk.

But this intention of nature appears more evidently in the ruminating quadrupeds; for I find that a fubftance connected with the internal carotid artery, obferved by Galen and named by him rete mirabile, which by Heifer and others has been called plexus vaforum et fibrarum, ufus incogniti *, confifts entirely of a divifion of that artery into fmall ferpentine branches, which are afterwards collected, at the fide of the fella turcica, into a trunk that is divided nearly as in man + ; and the vcrtcbral arteries, I likewife obferve, form a rete mirabile.

But, although the momentum of the blood is thus broken, the quantity of it which circulates in the brain is greater than in moft organs of the fame weight. Thus one of our arms will be found to weigh more than our brain and cerebellum; yet the areae of the two vertebral and of the two internal carotid arteries, joined together, are much larger than the area of the proper fubclavian artery.

This

Sce Heifler Comp. Anat. p. ${ }_{13}^{8}$. $\$ 27.3$.

+ Sec T. I. moderately filled, and the pia mater was, upon the whole, paler, and less vascular. Kellie also performed a literature review and found a description of a similar case by Morgagni: Cutis cranium tegens interiore facie sanguiferis turgebat vasculis. Cerebrum nihil, quantum judicare sensus poterant, ab naturali constitutione discrepebat (the veins within the scalp were engorged. Nothing in the brain, so far as we were able to judge, differed from its natural appearance). ${ }^{7}$ In these cases, the extracranial vessels were very congested; in the intracranial space: sinuses and veins were but moderately filled and the arteries contained little blood. Kellie then describes the case of a patient with long-lasting anemia: The body in general was nearly bloodless. On dividing the integuments of the cranium, a reddish serum only flowed out. [...] The dura mater was uncommonly pale, bloodless, and transparent, except only in the course of the longitudinal sinus, which was distinguished by a faint pink tint. [...] The larger vessels ramifying over the hemispheres, and between the convolutions of the brain, were all conspicuous, from the color given to them by the same pale pink-colored fluid, with which they were filled, though not distended. The vessels of the basis of the brain, cerebellum, and medulla elongata, contained little or no colored fluid. [...] The vessels of this brain, however, are far from furnishing an example of unqualified depletion. Compared with the rest of the body, I would say that they contained more than the usual relative quantity of fluid which had circulated during life. Also in this case, the quantity of intracranial blood was much more usual than the extracranial blood, with veins full of little colored fluid and arteries with little or no fluid inside.

In conclusion, the cause of death has no influence on the intracranial quantity of blood, which is distributed between arteries and veins.

\section{Kellie's animal experiments}

In order to determine the effect of exsanguination and posture, Kellie performed a series of animal experiments (using sheeps and dogs).

$A, G$, and $H$, are examples of depletion from simple arterial hemorrhage; $B$ and I, of uncomplicated venous hemorrhage. $C$ and $D$ afford examples of more rapid hemorrhage and death, from the knife of the butcher. In E the carotids were tied, with the view of arresting the expectation of voiding the brain to the greatest possible extent. In $F$, on the contrary, the jugulars were tied with the view of obstructing the return of blood from the head, while one carotid artery was laid open, and the animal allowed bleeding to death as a comparative 
experiment.

Kellie therefore concludes that: In our dissections, we do not meet with very striking varieties in the appearances of those vessels: the sinuses of the dura mater, and the veins in general, are found filled, or congested. Even the brains of those who have been largely depleted during life, or who have sunk from inanition, does not appear much voided of their blood. The brains of our apoplectic patients themselves, whom we have, in the course of one or two days, of a few hours perhaps before death, bled to a great extent, with the very purpose of unloading their vessels, are still found congested with blood. In animals bled to death, the brain still retains much of its blood; the vessels on its surface are red, well filled, and sometimes exhibit the appearance even of turgidity and congestion.

In conclusion, what Monro, Kellie and Abercrombie demonstrated was perfectly expressed in these sentences by Monro, describing what happens during each cardiac cycle: as the substance of the brain, like that of the other solids of our body, is nearly incompressible, the quantity of blood within the head must be the same, or very nearly the same, at all times, whether in health or disease, in life or after death.

It does not, however, follow from this, that every individual artery or vein within the head is constantly of the same size, or that, at all times, it contains the same quantity of blood, and, of course, that the arteries within the head are immoveable, like metalline tubes, or want pulsation [...]. For, whilst the heart is performing its systole, the arteries here, as elsewhere, may be dilating, and, in the mean time, a quantity of blood, equal to that which is dilating them, is passing out of the head by the veins. During the succeeding period of diastole of the heart and systole of the arteries, the quantity which dilated the arteries of the brain passes into the corresponding veins and sinuses; at the same time, as much passes from the sinuses out of the head, as enters into the head from the contracting trunks of the arteries situated between the heart and the head (Figure 2).

The original Monro-Kellie doctrine is therefore a dynamic explanation of the intracranial system, aimed at explaining how a pulsatile and continuous perfusion may occur in a closed and fully filled system. Monro implicitly states that the blood coming out from the cerebral veins into the sinuses must be pulsatile and (almost) synchronous with the arteries. That is deeply different from the concept of a constant content of a rigid case, as expressed by Cushing.

\section{Actuality of Monro-Kellie- Abercrombie}

The original Monro doctrine has therefore been neglected for centuries. At present, the available models on the intracranial system do not consider that doctrine as is, but as a static, fully filled container. The correct application of the doctrine could revolution the knowledge of the intracranial system and help to understand the pathophysiology of several conditions in which the intracranial system homeostasis is impaired. In the original doctrine, Monro, Kellie and Abercrombie did not consider two fundamental elements. The first is the so called Starling resistor, which is located at the level of the bridging veins (Starling described it several years later). The second is the little knowledge of the effects of gravitation on the human body: the authors improperly talk about the effects of the atmosphere in their observations. Instead, the force determining modifications leading to conditions such as the sinking skin flap syndrome after removal of a portion of skull (the sinking skin flap syndrome resembles the animal experiments of Kellie) is gravitation.

\section{References}

1. Macintyre I. A hotbed of medical innovation: George Kellie (1770-1829), his colleagues at Leith and the Monro-Kellie doctrine. J Med Biogr 2013;22:93-100.

2. Cushing H. Studies in intracranial physiology and surgery: the third circulation, the hypophysics, the gliomas. London: $\mathrm{H}$. Milford, Oxford University Press; 1926.

3. Herbowski L. The Maze of the cerebrospinal fluid discovery. Anat Res Int 2013;2013:8.

4. Kellie G. An account of the appearances observed in the dissection of two of three individuals presumed to have perished in the storm of the $3 \mathrm{~d}$, and whose bodies were discovered in the vicinity of leith on the morning of the 4th, November 1821: with some reflections on the pathology of the brain. Trans Med Chir Soc Edinb 1824;1:84-169.

5. Monro A. Observations on the structure and functions of the nervous system: Illustrated with tables / By Alexander Monro. Edinburgh: printed for, and sold by, William Creech and Joseph Johnson, London; 1783.

6. Abercrombie J. Pathological and practical researches on diseases of the brain and the spinal cord. Edinburg: Waugh and Innes; 1828.

7. Morgagni G, Chaussier F, Adelon NP. De sedibus et causis morborum per anatomen indagatis: libri quinque: in quibus continentur dissectiones et animadversiones propemodum innumerae, medicis, chirurgis, anatomicis profuturae. Paris: Apud M. C. Compère; 1820. 